\title{
Previsão de Vendas e Dados Estatísticos: o Caso da Woodstock e suas Exportações para os EUA
}

\author{
Sales Forecast and Statistical Data: the Woodstock Case and its Exports to the USA
}

\author{
Charles Agostini \\ Universidade do Vale do Itajaí - Univali - Brasil \\ charlesag@unidavi.edu.br \\ ORCID: 0000-0001-5469-5141 \\ Raul Beal Partyka \\ Universidade do Vale do Itajaí - Univali - Brasil \\ raul@edu.univali.br \\ ORCID: 0000-0001-7941-2152 \\ Jeferson Lana \\ Universidade do Vale do Itajaí - Univali - Brasil \\ jlana@univali.br \\ ORCID: 0000-0002-9787-1114
}

Submetido em 24/08/2018; Aprovado em 01/10/2018

\section{Resumo}

Este caso para ensino relata o dilema da empresa Woodstock, uma fabricante de portas de madeira. Seu principal mercado consumidor está nos Estados Unidos da América. A empresa, ao longo dos anos, tem apresentado altos e baixos na produção e a necessidade de prever o comportamento do mercado só aumenta. Prever o consumo de portas ajuda a ter maior regularidade no fluxo de caixa e, consequentemente, na produção. 0 caso foi desenvolvido para oferecer aos alunos de comércio internacional e estatística, base para discussões sobre a eficiência da utilização de dados estatísticos secundários na previsão das vendas e oferecer maior regularidade a todo o sistema operacional de uma empresa. Espera-se que os alunos possam ter senso crítico diante da utilização dos dados estatísticos e olhar também para dentro da organização de forma a aproveitar os recursos disponíveis para atingir as metas de vendas e produção. Recomenda-se a utilização em cursos de Graduação e Pós-graduação, especialmente nas disciplinas de Internacionalização de Empresas, Estatística, Comércio Exterior e demais disciplinas que evoquem o tema de previsibilidade de vendas e estatística.

Palavras-chave: previsão de vendas, dados estatísticos, comércio internacional, caso para ensino.

\section{Abstract}

This teaching case relates the dilemma of Woodstock, a manufacturer of wooden doors. Its main consumer market is in the United States of America. The company, over the years, has shown ups and downs in production and the need to predict market behavior only increases. Predicting the consumption of doors helps to have greater regularity in the cash flow and, consequently, in production. The case was developed to provide students of international trade and statistics the basis for discussions about the efficiency of using secondary statistical data in sales forecasting and to provide greater regularity throughout a company's operating system. Students are expected to have a critical sense of using statistical data and also look inside the organization to take advantage of available resources to achieve sales and production goals. It is recommended to use in undergraduate and postgraduate courses, especially in the subjects of Internationalization of Companies, Statistics, Foreign Trade and other disciplines that evoke the subject of sales predictability and statistics.

Keywords: sales forecast, statistical data, international trade, teaching case.

\section{Introdução}

Em 1938, dois irmãos chamados Guilherme e Heitor, fundaram uma pequena marcenaria com 
uma única máquina vinda da Alemanha. Com o passar dos anos, a empresa passou a fabricar pequenos artefatos de madeira e também virou referência na produção de carreteis, alavancada pela ampla expansão do setor elétrico advinda da criação de hidrelétricas na região. 0 segmento atual da empresa, que se caracteriza pela produção de portas de madeira, teve início nos anos 80. Desde então, é a produção de portas que traz um grande crescimento e reconhecimento a Woodstock. Tal reconhecimento trouxe aumento dos lucros, do tamanho da empresa, do número de funcionários e da área de atuação, chegando a exportar para diversos países do globo.

A partir do momento que a empresa passou a exportar para os EUA, precisou-se entender sobre o consumo de portas pelo mercado norte-americano. 0 responsável por este levantamento e construção das estatísticas, foi o gerente comercial Lucas. Ele ficou encarregado de utilizar todos os recursos disponíveis além de poder contratar profissional especializado, para apresentar tudo ao Sr. Artur, diretor da empresa. 0 risco era produzir demais ou de menos. Lucas sabia que portas estocadas trariam um grande montante de capital de giro envolvido. Sabia também que, caso os pedidos de exportação crescessem e a empresa não tivesse condições de entregar, perderia os clientes americanos. Como poderia Lucas prever as vendas da empresa? Uma solução encontrada por ele, foi a sugestão de um indicador disponibilizado pelo governo americano que trazia informações sobre pedidos de novas casas e reformas de casas já existentes.

Em posse desse índice, Lucas chegou a gráficos e análises de regressão e correlação. Portanto, o dilema do caso é: até que ponto o consumo de materiais de construção americano ajuda a prever as vendas e, consequentemente, a produção da Woodstock?

\section{Antecedentes históricos}

Os irmãos Guilherme e Heitor sempre tiveram paixão por máquinas e estavam sempre curiosos a respeito das novidades sobre esse segmento. A pequena cidade de Salete, no interior do estado de Santa Catarina, com seus aproximados 4.000 habitantes no ano de 1938, parecia pequena para os pensamentos à frente da época destes dois irmãos. Neste mesmo ano resolveram instalar uma pequena marcenaria para fabricar variados artefatos de madeira, utilizando uma máquina que haviam comprado da Alemanha. Em pouco tempo os dois irmãos ficaram conhecidos na região pela qualidade de seus produtos e com a seriedade com que desenvolviam seus móveis e outros utensílios de madeira. Fabricavam armários, camas, mesas, bancos, móveis para igreja, dentre outros produtos, utilizando madeira de qualidade garantindo um acabamento impecável e duradouro. Houve então, a necessidade de ampliar seus negócios e contratar mais funcionários.

Guilherme sempre teve muito fascínio por máquinas e desenvolveu alguns exemplares para utilizar em sua pequena fábrica. A empresa Woodstock, alcançou muito profissionalismo e começou a explorar outros segmentos de produtos ainda relacionados à madeira. Em 1957 a empresa começou a produzir carreteis de madeira utilizados fios de iluminação. No Brasil por esta época, começou uma forte expansão no setor elétrico com a criação de hidrelétricas usavam-se muitos carreteis para transportar os fios para os lugares mais remotos. A Woodstock, até o ano de 1983 foi uma referência na fabricação de carreteis e tinha um grande volume de venda deste produto. Houve época, por volta do ano de 1975, em que saiam cerca de 20 caminhões por dia e as cargas destinadas, em sua maioria, iam para os estados de Minas Gerais e São Paulo.

Na década de 80, a Woodstock, com uma fábrica mais ampla e com aproximadamente 500 funcionários, começou a produzir portas de madeira, atendendo de início o mercado nacional brasileiro. Muito em breve, por meio de clientes que tinham negócios de representação internacional, começaram a desenvolver e prospectar o produto para exportação. Assim se fez o primeiro container de teste vendido para os Estados Unidos em 1984. Um sucesso! Após iniciar venda regular para os Estados Unidos, a empresa começou a buscar outros mercados, como Inglaterra, Espanha, Alemanha, no entanto o mercado norte-americano sempre se mostrou com demanda maior e mais regular, se tornando assim, o principal mercado consumidor para as portas Woodstock. No quadro 1 se consegue visualizar a linha do tempo das atividades da empresa Woodstock.

No ano de 1999, a empresa Woodstock sentiu a necessidade de expandir de forma agressiva na produção de portas para atender a clientes norte-americanos, que se mostravam cada vez mais promissores e apresentavam capacidade de consumo elevado. Criara-se a Woodstock II, uma fábrica nova, localizada na cidade de Pouso Redondo/SC e toda desenvolvida para a produção de portas sem nós, no padrão que é consumido pelos Estados Unidos. 


\begin{tabular}{ll}
\hline $\mathbf{1 9 3 8}$ & Criação da empresa pelos irmãos Guilherme e Heitor \\
\hline $\mathbf{1 9 5 7}$ & Início da produção de bobinas para fios de eletricidade \\
\hline $\mathbf{1 9 8 3}$ & Início da produção de portas em larga escala para o mercado nacional \\
\hline & Inauguração da unidade II \\
\hline
\end{tabular}

Quadro 1. Linha do tempo das atividades da Woodstock

Fonte: elaborado pelos autores.

Na década do ano 2000, as duas fábricas possuíam capacidade de produção de 70 mil portas por mês e contavam com aproximadamente 1.200 funcionários. A Woodstock, agora administrada pelo filho do fundador Guilherme, Sr. Arthur, estava com uma produção regular dentro de uma estrutura implantada automatizada, e a cada ano ampliando e melhorando o processo de fabricação de portas de Pinos de forma muito profissional e competitiva. A empresa viu neste negócio o carro chefe que iria alavancar a empresa e consolidá-la efetivamente no mercado internacional na produção de portas para construtoras, atacadistas e lojas especializadas.

No entanto, com a estrutura já montada, observou-se que havia períodos em que o setor produtivo vivenciava certa ociosidade e outros períodos em que a fábrica não conseguia atender toda a demanda. Como uma empresa familiar, muitos métodos de administração e gerenciamento foram aprendidos no decorrer de cada necessidade. A alta e baixa no volume de vendas geraram uma necessidade de saber como melhor gerenciar estas situações. Procurou-se então obter métodos para prever demandas. Desta forma, procurava-se conhecer quais os períodos de maior e menor consumo e como o mercado de construção dos Estados Unidos estava se comportando dentro do consumo para materiais de construção, especificamente, portas de madeira. Era o momento de conhecer mais a fundo sobre o consumo deste material pela população norte-americana, principal mercado internacional.

\section{Prevendo as vendas}

Com o objetivo de entender mais a fundo sobre o consumo de portas pelo mercado norteamericano, além das rotineiras viagens de negócios, o gerente de vendas, Lucas, iniciou um estudo de análise de índices disponibilizados pelo governo dos Estados Unidos, onde se obtém números de novas construções autorizadas pelas prefeituras ao longo de todo país, separado por estados. Esses relatórios são elaborados e disponibilizados pelo Censo norte-americano e são divulgados mensalmente em seu portal na internet. De início mostrou-se bastante árduo o trabalho de conhecer e analisar estes dados. Bastava agora saber se eles serviriam para elaborar uma previsão de vendas para o grupo Woodstock.

A permissão para construções de novas residências nos EUA é um procedimento para autorizar alguém a executar uma nova construção. Dessa forma, é índice interessante para previsão de demanda para materiais de construção. A autorização para novas residências leva em conta os diferentes tipos de obras realizadas e, nos Estados Unidos, são quatro os tipos de residências consideradas para este índice: 1 Unit (1 Unidade): Representam uma casa para uma única família. Um terreno com uma única casa. É o tipo de residência mais comum. A referência para este tipo de residência, se identifica na Figura 1.

As 2 Units (2 Unidades): Representam uma casa dupla (Figura 2). Duas casas juntas, um único terreno, um único prédio onde duas famílias podem viver. É o segundo tipo mais comum de residência nos Estados Unidos.

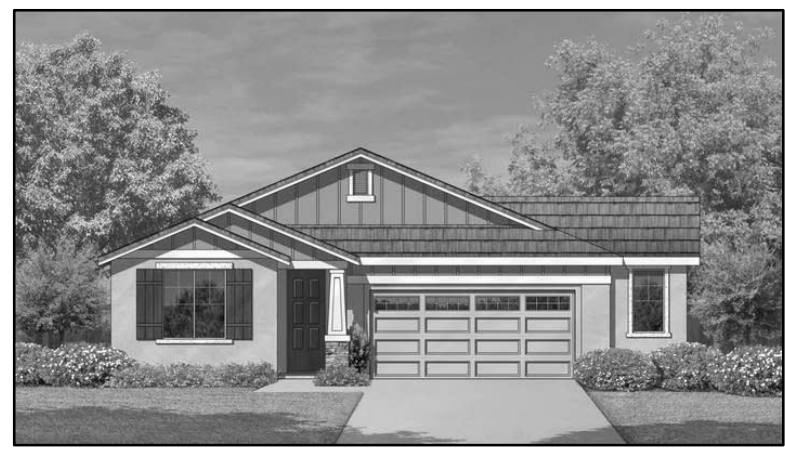

Figura 1. Modelo de residência do tipo 1 Unit Unifamiliar.

Fonte: Open Listings (2017)

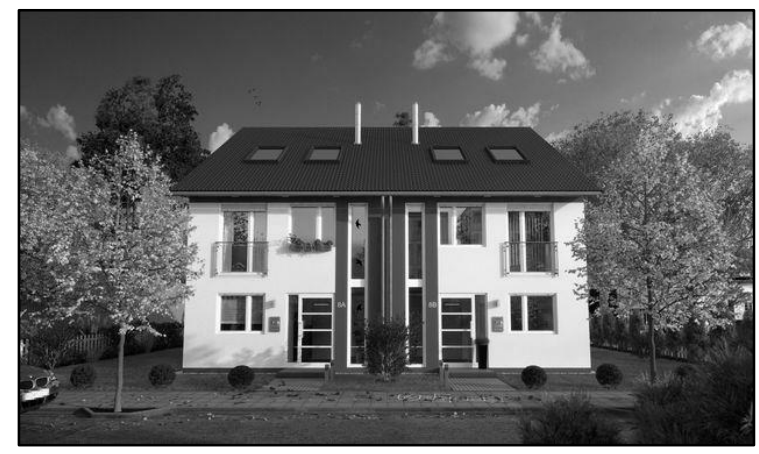

Figura 2. Modelo de residência do tipo 2 Unit - 2 Unidades.

Fonte: Cgarchitect (2017) 
As 3 and 4 Units (3 e 4 Unidades): São 3 ou 4 casas construídas juntas e que servem para 3 ou 4 famílias. Estas casas são mais pequenas com dois quartos e ficam geralmente próximas a universidades para servirem como casas de estudantes (Figura 3).

As 5 Units or More (5 Unidades ou mais) são o terceiro tipo mais comum de residências. São apartamentos com 1 até 3 quartos e são construções que servem para várias famílias. A Figura 4 ilustra este tipo de residência.

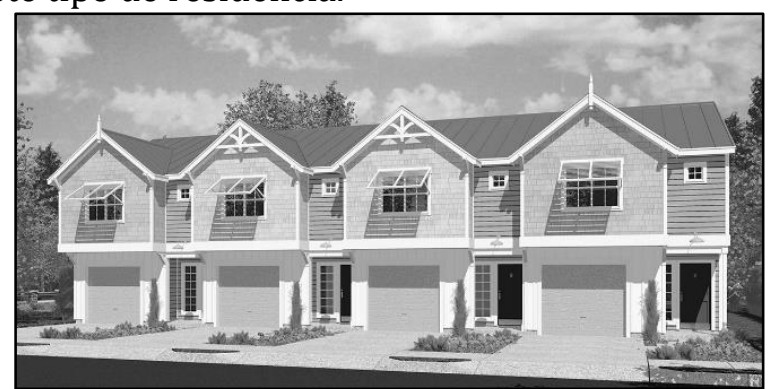

Figura 3. Modelo de residência do tipo 3 and 4 Unit - 3 ou 4 Unidades.

Fonte: Houseplans (2017)

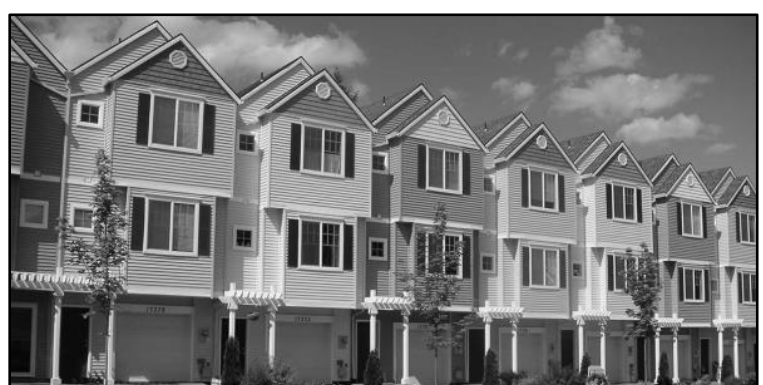

Figura 4. Modelo de residência do tipo 5 or more Units - 5 ou mais Unidades.

Fonte: Houseplans (2017)

Não se pode estimar com muita precisão quantas portas vão em cada uma destas residências, pois elas podem mudar dependendo do número de ambientes que a família deseja montar. Porém, pode-se estimar considerando uma média de que as residências 1 Unit possuem 3 quartos, 2 banheiros, closets cozinha e área de serviço e desta forma precisaria de 12 a 15 portas, o mesmo podemos estimar para as 2 Units ou um pouco menos, pois são residências um pouco menores. Os apartamentos têm geralmente de 1 a 2 quartos, dessa forma, o número de portas ficaria em torno de 6 ou 7 portas.

Além das novas construções, as empresas fabricantes de portas, também devem colocar sua atenção para o consumo de seus produtos em reformas. Porém, por um estudo prévio junto de seus principais clientes, a Woodstock observou que o consumo de portas estava muito maior para novas construções, portanto, é para este mercado que a empresa decidiu voltar sua análise para exercitar sua capacidade de previsão de consumo de portas de madeira no mercado consumidor norte-americano.

Desde que essa análise começou a ser feita na empresa por Lucas, gerente comercial, notou-se que a curva do gráfico das vendas de portas realizadas pela empresa, seguia de certa forma a curva das autorizações de novas construções, consolidando os quatro tipos de residências, no mesmo período. No entanto, existiam períodos em que as vendas da empresa estavam abaixo do que se estimava com os dados analisados. 0 gerente começou a depositar uma certa desconfiança diante do modelo adotado para prever o consumo de portas justificando que o mercado apontava para uma direção divergente dos índices de autorizações de novas residências.

\section{A bola de cristal}

Para que se tivesse maior certeza sobre o método de previsões, Lucas, o gerente comercial, procurou alguns professores de estatísticas para que obtivesse alguma informação sobre a validade dos dados que estavam sendo observados e se eles eram realmente úteis para prever consumo. Teve o aval do diretor da empresa, Sr. Artur. O professor escolhido foi o Prof. Motta, respeitado estatístico de uma Universidade na região do Alto Vale do Itajaí, pegou os dados de 2004 a 2018, contendo o número de autorizações de novas residências, e comparou com o montante em dólares de exportações do NCM (Nomenclatura Comum do Mercosul) 44182000, que são as portas e seus respectivos caixilhos e alisares realizado pelo Brasil aos Estados Unidos da América no mesmo período e obteve o quadro 2:

\begin{tabular}{|l|rrrrr|rrr|}
\hline & Obs Mean & \multicolumn{1}{c}{ Std. Dev. } & \multicolumn{1}{c}{ Min } & \multicolumn{1}{c}{ Max } & (1) & (3) \\
\hline (1) Exportação da NCM & 156 & $9,478,082.00$ & $2,761,460.00$ & $3,790,140.00$ & $17,200,000.00$ & 1 & \\
(2) Número de Pedidos & 156 & $98,984.18$ & $45,984.49$ & $36,280.00$ & $211,944.00$ & $0.7124^{*}$ & 1 & \\
(3) Dólar Médio & 156 & 2.31 & 0.60 & 1.57 & 3.99 & $0.4529 *$ & $0.3861 *$ & 1 \\
\hline
\end{tabular}

Quadro 2. Estatística Descritiva e Matriz de Correlação

Fonte: Elaborado pelo autor.

- Que loucura é essa? Exclamou Sr. Artur, diretor da empresa. 
- Que tanto de número é esse? Texto em inglês? Números separados por vírgulas e não por pontos? O que é isso, Prof Motta? Continuou o diretor.

0 professor Motta esboçou um sorriso e ficou contente com a curiosidade de Artur. Disse ele: - Calma, Sr. Artur. Estou rodando os dados em um software em inglês, mas o Excel daria os mesmos resultados. Compreenda, o que temos na tabela é: o número de observações, no caso 156 meses. A média (mean) de cada uma das variáveis, o desvio padrão (Std. Dev) e os valores mínimos (Min) e máximos (Max) de cada variável. Por fim, nas colunas (1), (2) e (3), é uma pequena matriz de correlação. Por ela, o Sr. pode verificar que há uma grande correlação entre a exportação brasileira de portas e o número de pedidos.

- Posso ver? Onde? Não estou vendo nada, homem de Deus! Não sei o que significam esses números!! Respondeu o Sr. Artur ainda desnorteado.

- Artur, me permita! Disse Lucas, gerente comercial.

- Fui aluno do Prof. Motta e lembro de algumas coisas. Basicamente, quando a matriz de correlação mostra um coeficiente maior que 0,70 em módulo, significa que há uma forte correlação entre as variáveis. No nosso caso, a correlação entre as exportações brasileiras e o número de pedidos de novos imóveis nos EUA é de $71,24 \%$. Isso indica que há sim possibilidade de que os pedidos de novos imóveis americanos possam prever as exportações, não é isso Prof. Motta?

0 professor orgulhoso do ex-aluno respondeu:

- É isso sim, Lucas. Não podemos afirmar que uma variável causa a outra, pois temos apenas evidência de correlação, mas também nem é nossa intenção aqui comprovar causas. Queremos apenas saber se um aumento no número de novos imóveis americanos é seguido por um aumento do número de exportações, $e$ a resposta é que sim. Na verdade, podemos inclusive encontrar um coeficiente de covariância, utilizando uma regressão linear multivariada.

- Sem cebola, por favor!! Ironizou Sr. Artur, demonstrando não fazer ideia do que o Prof. Motta estava falando.

Lucas voltou a interceder, e disse:

- Patrão, fica calmo. O que o Prof. Motta quis dizer é que podemos tentar entender não apenas a correlação, mas também quanto de aumento de uma variável, afetaria a outra. Mostre a regressão, Prof. Motta. Eu explico ao Artur.

\begin{tabular}{|c|c|c|c|c|}
\hline VARIÁVEIS & $\begin{array}{c}1) \\
\text { Model } 1.1 \\
\end{array}$ & $\begin{array}{c}(2) \\
\text { Model } 1.2 \\
\end{array}$ & $\begin{array}{c}3) \\
\text { Model } 1.3 \\
\end{array}$ & $\begin{array}{c}(4) \\
\text { Model } 1.4 \\
\end{array}$ \\
\hline $\begin{array}{l}\text { Pedidos de novas } \\
\text { residências }\end{array}$ & $42.78^{* * *}$ & & & $60.70^{* * *}$ \\
\hline Dólar Médio & & $\begin{array}{c}2.088 \mathrm{e}+06^{* * *} \\
(330,583)\end{array}$ & & $\begin{array}{l}-408,463 \\
(316,583)\end{array}$ \\
\hline Ano em que ocorreu & & & $\begin{array}{l}-65,965 \\
(58,373)\end{array}$ & $\begin{array}{c}357,984^{* * *} \\
(54,368)\end{array}$ \\
\hline Intercepto & $\begin{array}{c}5.243 \mathrm{e}+06^{* * *} \\
(362,875)\end{array}$ & $\begin{array}{c}4.657 \mathrm{e}+06^{* * *} \\
(777,505)\end{array}$ & $\begin{array}{c}1.421 \mathrm{e}+08 \\
(1.173 \mathrm{e}+08)\end{array}$ & $\begin{array}{c}-7.151 \mathrm{e}+08^{* * *} \\
(1.090 \mathrm{e}+08)\end{array}$ \\
\hline $\begin{array}{l}\text { Observações } \\
\text { R-quadrado }\end{array}$ & $\begin{array}{c}156 \\
0.508\end{array}$ & $\begin{array}{c}156 \\
0.205\end{array}$ & $\begin{array}{c}156 \\
0.008\end{array}$ & $\begin{array}{c}156 \\
0.636\end{array}$ \\
\hline
\end{tabular}

Robust standard errors in parentheses. ${ }^{* * *} \mathrm{p}<0.01,{ }^{* *} \mathrm{p}<0.05,{ }^{*} \mathrm{p}<0.1$

Quadro 3. Tabela de regressão

Fonte: elaborado pelo autor

- Veja patrão, na última coluna. O coeficiente de pedidos de novas residências foi de 60,70. Isso significa que há uma relação entre as variáveis tal que a cada novo pedido de residência nos EUA, a exportação brasileira apresenta uma alta de USD 60,70 dólares. Logo, se mensalmente a média de pedidos de novas residências nos EUA foi de quase 100 mil casas, logo, é possível esperar variações de 6 milhões de dólares em exportação, que somam uma média de aproximadamente 9 milhões de reais. E olha que legal, o $R$ 
quadrado deu quase 64\%. Prof. Motta, lembro que isso é bom, mas acho que não sei explicar ao Sr. Artur. Me ajuda nessa. Disse Lucas.

- Ótimo, já não sou o perdido aqui! Voltou a brincar o Sr. Artur

- Claro, deixa comigo. Disse Motta a Lucas.

Dirigiu-se a Artur, e disse:

- Um R quadrado de 64\% significa o seguinte. Dentro de toda a variância que houve mensalmente nas exportações de portas brasileiras aos EUA nesses 156 meses, só os pedidos de novos imóveis nos EUA respondem por praticamente 64\%. Logo, sim... esse indicador pode sim ajudar vocês a preverem o número de exportações futuras. Mas cuidem sempre que há uma diferença grande entre correlação e causa. Disse o Prof. Motta já se preparando para deixar a sala.

Lucas ainda quis mostrar para o Sr. Artur essa relação de forma mais visual. Levando em consideração a tabela dos modelos de regressão, os valores em dólares das exportações brasileiras do NCM 44182000, em comparação com a quantidade de autorizações de novas residências nos Estados Unidos, pode ser um índice relevante para prever o consumo de portas de madeira para aquele país?

Analisando os dados utilizado no sistema de Regressão em um gráfico agrupado, pode-se observar uma curva muito homogênea entre a relação do número de autorização de novas residências com os valores em dólares das exportações brasileiras deste NCM para os Estados Unidos, como pode-se ver no gráfico mostrado na Figura 5.

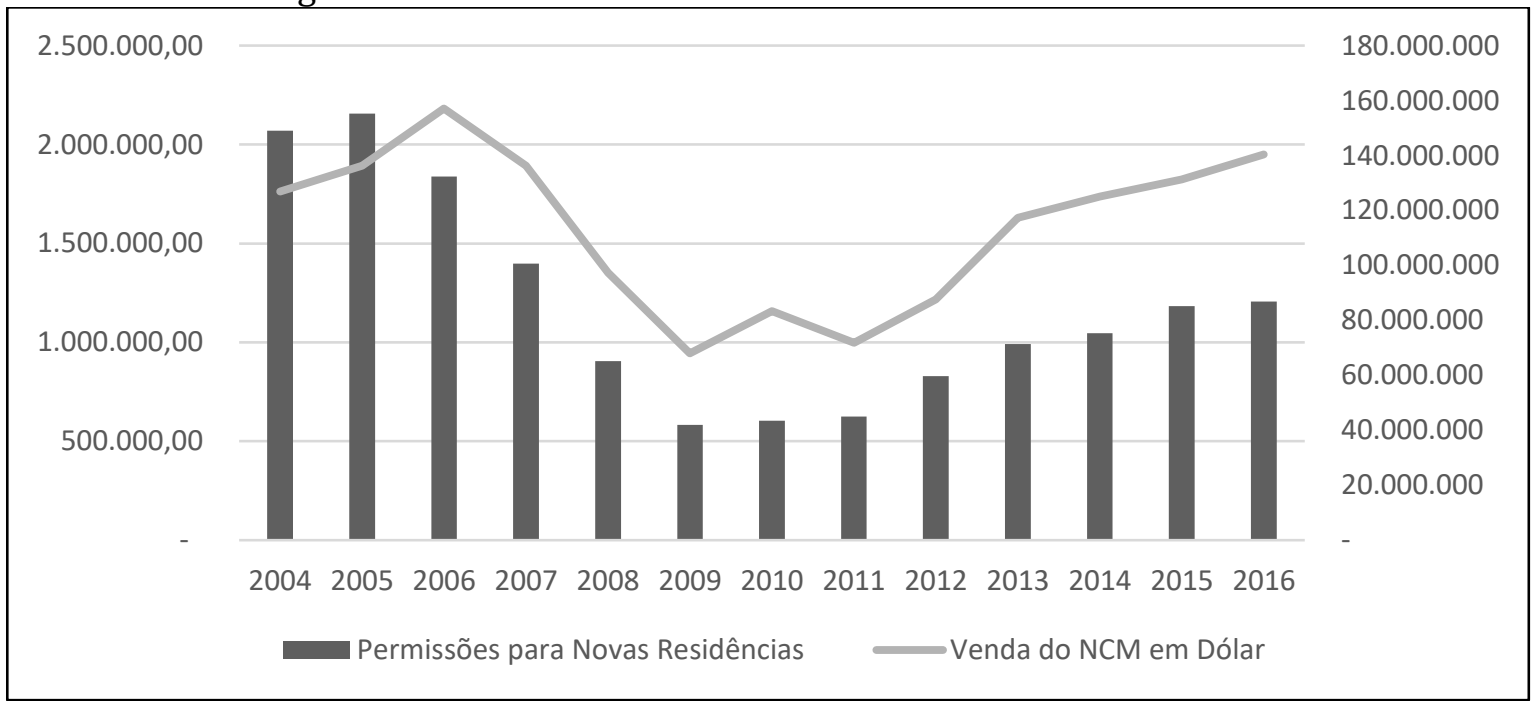

Figura 5. Gráfico Permissões para novas residências norte-americanas versus vendas brasileiras para os Estados Unidos

Fonte: Elaborado pelo autor com base em Website Census (2017) e Website System Of Analysis of Foreign Trade Information (2017).

Munidos destes dados na forma de gráfico, pode-se considerar relevante para a empresa Woodstock utilizar o indicador fornecido pelo Censo norte-americano para formar sua previsão de vendas de maneira mais assertiva? 


\section{NOTAS DE ENSINO}

As notas de ensino estão construídas para o acesso exclusivo aos docentes. Elas possuem o intuito de direcionar os objetivos, sugerir questões de discussão, abordar a forma de aplicação do caso e analisar a história com base nas teorias.

\section{Sinopse}

As empresas e indústrias buscam continuamente ferramentas que as auxiliem a estimar demandas e futuras vendas, com o objetivo de melhor programar suas atividades e verificar como está sua participação no mercado. É importante situar as atividades da empresa em relação aos fatos históricos e assim fazer projeções para o futuro, possibilitando um melhor planejamento e redução de custos. Com esta afirmação, é importante para a empresa estabelecer o exercício de prever, especialmente quando se trata de vendas. Isso se deve pela demanda por determinado produto, ao trazer auxílio para determinar a programação de produção e a capacidade instalada. Em suma, dar os caminhos para o negócio. As previsões estão baseadas em fatos históricos ou tendências de determinado períodos para os produtos em questão.

O objetivo deste estudo é discutir a capacidade da utilização de dados estatísticos secundários, neste caso fornecidos pelo governo estadunidense de autorizações de novas residências naquele país, para estimar previsão de vendas da empresa Woodstock. Com estes dados, pode-se estimar o consumo de materiais de construção, mais especificamente, portas de madeira. Estes dados são atualizados e divulgados mensalmente e separado por estados americanos. Com isso, pode-se detectar qual região está com seu consumo mais elevado e se a região, já atendida pela empresa, está com o consumo em crescimento, baixa ou estabilizado.

\section{Fontes de dados}

A coleta dos dados para obtenção dos índices estatísticos foi realizada na página de internet do United States Census Bureau (2017). Nesta página, pode-se ter informações mensais de autorizações de novas residências (Building Permits) realizada pelo governo norte-americano à população que deseja construir uma nova residência. Quanto aos dados de valores em dólares das exportações brasileira para os Estados Unidos do NCM 44182000, portas de madeira e respectivos caixilhos e alisares, foram colhidos do Website System Of Analysis of Foreign Trade Information (Alice Web) (2017) que é um sistema de Análise das Informações de Comércio Exterior ligado ao MDIC (Ministério de Desenvolvimento da Indústria e Comércio Exterior). Foram realizadas entrevistas à empresa para obtenção dos antecedentes e histórico de crescimento e consequentemente para entender sobre o dilema apresentado neste caso para ensino. 0 nome da empresa e os nomes dos personagens são fictícios, para preservar a identidade, porém, não alteram o contexto do caso. 0 roteiro e acontecimentos são reais. As informações coletadas, quando transcritas, foram adaptadas para formar enredo necessário no método caso para ensino.

\section{Objetivos educacionais}

O presente caso tem o objetivo pedagógico de estimular a discussão sobre a capacidade de previsibilidade de vendas pelas empresas que atuam no comércio internacional. São várias as formas de métodos que podem ser utilizados pelas empresas para prever o consumo de seus produtos, o presente caso, apresenta uma forma de análise com base em dados estatísticos disponibilizado pelo Censo norteamericano.

Ao ser aplicado este caso para os alunos, o professor perceberá que será de fácil leitura e entendimento do dilema central que trata da confiabilidade do método usado para prever as vendas. Tem-se os dados de autorizações para novas construções, reproduzido no sistema estatístico de regressão em comparação às vendas brasileiras do NCM deste produto, dessa forma encontra-se o índice de confiabilidade deste método e se o mesmo se demonstra relevante para o que a empresa busca, que é prever as vendas e desta forma ajustar a capacidade instalada para produção de portas de madeira.

\section{Sugestão de questões para discussão}

Foram elaboradas questões que possam auxiliar no processo de aprendizado. As questões apresentadas a seguir podem ser utilizadas de acordo o objetivo educacional, e estão classificadas em 
dois eixos temáticos. Desta forma, elas podem ser utilizadas por completo ou em separado, de acordo com a necessidade e disciplinada aplicação.

\section{1) Questões sobre previsão de vendas}

a) De que forma a previsão de vendas pode auxiliar a gestão da empresa Woodstock?

b) Considerando os antecedentes da empresa Woodstock, pode-se afirmar que a empresa cresceu de forma ordenada, observando etapas de crescimento e se preocupando com demanda de consumo para montar sua capacidade instalada? Justifique sua resposta.

c) Em que momento percebeu-se ser necessário a utilização da ferramenta de previsão de vendas para a empresa Woodstock?

2) Questões sobre operacionalização da previsão de vendas

a) Qual a aplicabilidade do indicador norte-americano de novas construções para a empresa Woodstock prever as suas vendas?

b) Analisando a tabela de regressão, pode-se considerar de que a empresa está utilizando um índice de relevância para prever as vendas? Justifique.

c) De que forma é possível calcular a produção de portas de madeira analisando as permissões de construção para cada tipo de residência?

d) Identifique os principais aspectos estatísticos levantados no caso e explique suas utilidades para uma análise de previsão de resultados.

\section{Aplicação do caso}

Este caso para ensino foi construído para ser usado em cursos de graduação e pós-graduação de cursos de Administração de Empresas e demais cursos relacionados com gestão de negócios. A aplicação sugerida se dá em disciplinas como Orçamento empresarial, por ajudar na construção de cenários empresariais. Pode ainda ser utilizado em outras disciplinas, como Internacionalização de Empresas, Estatística, Comércio Exterior. Nas demais disciplinas que evoquem o tema de previsibilidade de vendas e estatística, também pode ser aplicado.

Como apoio ao professor, na aplicação do caso em sala de aula, apresenta-se duas sugestões para aplicação do caso em sala. A primeira (Quadro 4), uma sugestão de roteiro para discussão do caso, separado por seção. É importante garantir que os alunos leiam com atenção o caso antes da aula. Se isso não for possível, pode-se reservar um tempo de até 20 minutos, no início da sessão, para a leitura.

Quadro 4 - Plano de aula sugerido

\begin{tabular}{|c|c|}
\hline Questões & Seção \\
\hline Apresentação geral do caso, detalhando seus objetivos e o dilema. & Resumo \\
\hline $\begin{array}{l}\text { Descrevendo a situação-problema que requer análise. } \\
\text { 1. O indicador de consumo de materiais realmente é relevante para prever vendar? } \\
\text { 2. Quais outros índices poderiam ser utilizados no desenvolvimento de relatórios para a diretoria? }\end{array}$ & Introdução \\
\hline $\begin{array}{l}\text { Conceituando a história. Definição do local e época. } \\
\text { 1. Qual foi o estalo da empresa em determinar o principal produto no seu portfólio? } \\
\text { 2. O que estimulou os gestores a procurar métodos de previsão de demanda? } \\
\text { 3. Como você classifica a relação familiar desde a fundação da empresa? }\end{array}$ & $\begin{array}{l}\text { Antecedentes } \\
\text { históricos }\end{array}$ \\
\hline $\begin{array}{l}\text { Iniciava-se a etapa de desbravar dados acessíveis para construir as estatísticas gerenciais. } \\
\text { 1. Qual o nível de complexidade do índice coletado pelo gerente de vendas? } \\
\text { 2. Qual a importância da elaboração de um estudo que pudesse estimar a quantidade exata de } \\
\text { portas em cada tipo de residência? } \\
\text { 3. Já era possível identificar a premissa que promovia a maior demanda em novas construções? }\end{array}$ & $\begin{array}{l}\text { Prevendo as } \\
\text { vendas }\end{array}$ \\
\hline $\begin{array}{l}\text { O mercado é o principal motivador para a decisão estratégica do The Factory. } \\
\text { 1. Foi relevante a procura por um profissional experiente em estatística? } \\
\text { 2. Como poderia ser explicada mais detalhadamente a correlação apresentada? } \\
\text { 3. Descreva o resultado das quatro variáveis dos modelos de regressão. } \\
\text { 4. Embora tenha sido encontrado um R quadrado de } 64 \% \text {, como você descreve a diferença entre } \\
\text { correlação e causa? }\end{array}$ & A bola de cristal \\
\hline
\end{tabular}

Como segunda sugestão, apresentamos um plano alternativo de aula (Quadro 5), que pode promover a discussão do caso de uma forma mais abrangente, levando em consideração o perfil da turma, a quantidade de alunos, entre outras características. 
Quadro 5 - Plano de aula alternativo

\begin{tabular}{|lll|}
\hline $\begin{array}{l}\text { Tempo } \\
\text { Estimado }\end{array}$ & Atividade & $\begin{array}{l}\text { Conceitos } \\
\text { Mobilizados }\end{array}$ \\
\hline 5 -15 min & Apresentação geral do caso, detalhando seus objetivos & Objetivos \\
\hline 20-30min & $\begin{array}{l}\text { Discussão sobre as motivações e resultados esperados com } \\
\text { o objetivo proposto pelo caso. }\end{array}$ & Contexto \\
\hline & $\begin{array}{l}\text { 1) Sugestão: Formação de minigrupos. Distribuição dos } \\
\text { dois eixos temáticos de questões e levantamento de } \\
\text { soluções ou alternativas para estancamento dos } \\
\text { problemas. }\end{array}$ & \\
$\begin{array}{l}\text { 2) Sugestão: Discussão entre 3 grupos, com representantes } \\
\text { de: (i) dono da empresa, (ii) gerente e (iii) professor. }\end{array}$ & $\begin{array}{l}\text { Previsão de vendas estatísticos } \\
\text { 3) Sugestão: Criação de grupos múltiplos de 2, onde Comércio internacional } \\
\text { metade fica responsável por responder as questões } \\
\text { defendendo a utilização do método, e a outra parte } \\
\text { questiona a sua utilização, bem como explora os } \\
\text { participantes contrários para justificar a escolha. }\end{array}$ \\
\hline 15-20min & $\begin{array}{l}\text { Fechamento da aula com as devidas tomadas de decisão a } \\
\text { partir de então. }\end{array}$ & $\begin{array}{l}\text { Decisões da companhia perante o caso, a curto, } \\
\text { médio e longo prazo }\end{array}$ \\
\hline
\end{tabular}

\section{Análise do caso}

A leitura do caso sobre a previsão de vendas com base na análise estatística de dados fornecidos pelo governo norte-americano de autorizações para novas construções, vem trazer uma reflexão de que exercer a previsibilidade de vendas é uma atividade muito importante dentro de qualquer organização. A previsão da demanda é a base para o planejamento estratégico da produção, vendas e finanças de qualquer empresa, permite que os administradores destes sistemas antevejam o futuro e planeje adequadamente suas ações (Dias, 2010).

Os métodos estatísticos de previsão são ferramentas fundamentais para projetar comportamentos futuros, tendo como propósito a redução do risco na tomada de decisão. Normalmente, as previsões apresentam erros, mas a magnitude dos seus erros depende muito do sistema de previsão utilizado. Um dos maiores problemas associados à utilização das previsões de demanda no apoio à tomada de decisões é a escolha adequada do método de previsão a ser implementado. Diante disso, uma maior disponibilização de recursos no método de previsão escolhido, permite melhorar a precisão da previsão e, assim, eliminar alguns dos prejuízos resultantes da incerteza existente no processo de tomada de decisão. (Veríssimo et al., 2012).

São duas as divisões das técnicas de previsão de vendas: qualitativa e quantitativa. As previsões qualitativas são originadas de julgamento de especialistas ou de pessoas que possam, por experiência ou conhecimento adquirido, antever eventos de interesse ou correlacionar circunstâncias, de modo que possa gerar uma previsão de vendas em período futuro. Já as previsões quantitativas, se valem de recursos matemáticos e incluem o método casual e análise de série temporal. Ainda, na regressão linear há um relacionamento funcional entre variáveis correlacionadas. (Zan \& Sellito, 2007). Um parâmetro (variável independente) é usado para predizer outro (variável dependente), de modo linear, como na equação abaixo:

$$
\begin{aligned}
& \mathrm{Y}=\mathrm{a}+\mathrm{bX} \\
& \text { na qual: } \\
& Y=\text { variável dependente; } \\
& a=\text { intersecção no eixo } Y ; \\
& b=\text { inclinação; e } \\
& X=\text { variável independente. }
\end{aligned}
$$

A empresa Woodstock, sendo uma empresa familiar que foi crescendo observando cada etapa deste crescimento, viu-se na necessidade de estabelecer um método de previsibilidade para manter sua capacidade instalada com o mínimo possível de ociosidade e desta forma também se consolidar no mercado norte-americano na venda de portas de madeira. A previsão de vendas auxilia na gestão da empresa de forma a cumprir com sua missão de ser fornecedora de portas de qualidade atendendo as expectativas dos clientes. Como havia se observado que existiam períodos de menor ou maior consumo, 
a empresa buscou ao longo de sua trajetória ficar em uma situação em atender cada vez mais o mercado consumidor e utilizar de forma ordenada e alinhada sua capacidade produtiva. A previsão de vendas ajuda a empresa a planejar este crescimento, na ampliação da fábrica, construção de novas unidades, aquisição de máquinas e equipamentos, etc... tem-se uma ideia mais ampla do que está para acontecer. Uma previsão otimista pode auxiliar em todo o processo gerencial da empresa, desde compra da matéria prima até a medição de maiores taxas de faturamento, entretanto, uma previsão negativa pode, por consequência, desenvolver uma estratégia inversa, congestionando todo o processo produtivo (Las Casas, 2008).

0 indicador norte-americano, se mostrou eficiente no fornecimento de dados para estimar previsão de vendas, pois como o negócio da empresa Woodstock está mais voltado para novas construção e muito pouco para as reformas, pode-se ter uma ideia de que regiões ou estados estão em processo de maior expansão, e são nestas áreas que a empresa concentrará sua força de vendas. Com os indicadores mensais, pode-se observar uma tendência de crescimento e pode dar uma clareza maior sobre como a demanda por produtos de construção incluindo as portas, irá performar. Estes indicadores, comparados com o volume de exportações brasileiras do NCM 44182000 de portas de madeira no método estatístico de regressão, apresentam conclusões de que é sim relevante analisar estes dados, pois as vendas destes produtos estão diretamente ligadas ao aumento do consumo causado pelas novas construções.

Para cálculo de produtividade levando em consideração as quantidades de portas que o mercado norte-americano vai considerar, deve-se levar em consideração às diferentes classificações de residências sendo elas, 1 Unit, 2 Units, 3 and 4 Units e 5 Units or more. Cada uma destas classificações, se pode estimar o número de ambientes que elas terão, será desta forma que se poderá estimar o consumo de portas e prever o volume de produção e vendas. Certamente, a deve empresa continuar cumprindo seu papel em vendas e marketing para chegar nos principais polos consumidores e os convencendo a introduzir os produtos Woodstock dentro dos grandes distribuidores e lojas da área. Por fim, espera-se que aquilo que foi apresentado até aqui, possa contribuir para professores e alunos que estão realizando estudos sobre previsão de vendas e demanda.

\section{Referências}

Dias, G. P. P. (2010). Proposta de processo de previsão de vendas para bens de consumo. São Paulo, SP: EPUSP.

Las Casas, A. L. (2008). Administração em Vendas. 8 ed., São Paulo, SP: Atlas.

Salles, A. A., Arantes, P. E., \& Tavares, C. C. (2010) Um estudo da série de vendas de automóveis no Brasil através de métodos clássicos de previsão de demanda. Rio de Janeiro, RJ: EnANPAD.

Veríssimo, A. J., Alves, C. C., Henning, E., Amaral, C. E., \& Cruz, A. C. (2012). Métodos estatísticos de suavização exponencial holtwinters para previsão de demanda em uma empresa do setor metal mecânico. Revista Gestão Industrial, 8(4) 154-171.

Website United States Census Bureau (2017). Recuperado em 20 abr. 2017 de https://www.census.gov/construction/bps/.

Website System of Analysis of Foreign Trade Information (2017). Recuperado em 15 mai. 2017 de http://aliceweb.mdic.gov.br//.

Website Open Listings (2017). Recuperado em 23 set. 2017 de https://www.openlistings.com. Website Cgarchitect (2017). Recuperado em 23. set. 2017 de http://www.cgarchitect.com. Website Houseplans (2017). Recuperado em 23. set 2017 de https://www.houseplans.pro/. Zan, G. L., \& Sellito, M. A. (2007). Técnica de previsão de demanda: um estudo de caso triplo com dados de vendas de materiais eletro-mecânico. Carlos Barbosa, RS: Unisinos. 